\title{
Negara Islam V.S. Negara Yahudi \\ Analisis atas Alasan-alasan \\ Pendirian Negara dalam Islam dan Yahudi
}

\author{
Agus Triyanta
}

\begin{abstract}
In the modern age like this time, where secularization have penetrated in any human's views, but turn out the rest of people have not been destructed by secularization, including here is the view of compulsory for regulating political state with the religious institution in the Moslem and Jew communities. These writings are going to explain the problem of reason for establishing Islamic and Jew States.
\end{abstract}

\section{Pendahuluan}

Berbicara tentang negara Islam dan negara Yahudi, akan mengingatkan kita kepada begitu kuatnya sebuah agama mempengaruhi pemeluknya. Meski tesis tentang sekularisasi mengatakan bahwa sebuah agama, semenjak awal-awal modernisasi berproses, mulai kehilangan peran dalam berbagai sektor kehidupan manusia, namun tetap saja, agama (minimal dalam Islam dan Yahudi) tetap memiliki 'otoritas' yang kuat atas pemeluknya.

Banyaknya negara Islam di dunia ini, dan juga maraknya isu-isu pendirian negara Islam di berbagai kalangan muslim di dunia, mengisyaratkan secara jelas, bahwa negara Islam sebagai sebuah model, memang nyatanyata ada dan berlangsung di era modern ini.
Di sisi lain, gencarnya orang-orang Yahudi -termasuk juga non Yahudi yang pro terhadap Yahudi- untuk menegakkan negara Israel (the Modern Jewish State of Israel), juga mengisyaratkan bahwa bukannya tanpa latar belakang ideologis mengapa orang Yahudi tetap gigih untuk mempertahankan tegaknya negara Yahudi Israel. Dengan kata lain, bahwa Yahudi, sebagai sebuah agama yang banyak dianut oleh anak turun Bani Israel, memiliki ajaran tentang politik kenegaraan.

Pertanyaannya, mengapa negara agama tetap masih bertahan di era modern ini? Apakah alasan-alasan pembentukan negara (agama) dalam ajaran Islam (as-siyasah) dan dalam ajaran agama Yahudi. 


\section{Hubungan Agama dan Negara dalam Islam dan Yahudi}

Agama, dalam pandangan sosiolog keagamaan, memiliki cakupan wilayah pengaruh bagi para pemeluknya dalam, 4 (empat) aspek: restraint (pengendalian), representation (penampilan), reproduction (sosial-internal), serta registration (sosialeksternal). Restrain adalah hal-hal yang berhubungan dengan masalah yang dapat bersumber dalam diri pribadi, misalnya; dorongan untuk makan, hasrat-hasrat untuk melakukan sesuatu perbuatan tertentu. Representasi, adalah hal-hal yang berhubungan dengan penampilan luar seseorang, misalnya pakaian yang dipakai oleh seseorang, perhiasan mereka, serta tingkah laku mereka. Reproduksi, adalah permasalahan di seputar seksualitas dan penjagaan keturunan, termasuk seseorang memiliki anak banyak atau sedikit, dalam kelompok tertentu melarang homoseksualitas dan lesbianisme, dan kalangan yang lain tidak, sedangkan registrasi adalah seseorang membuat aturan-aturan dalam bersosialisasi dengan masyarakat di sekitarnya, termasuk di dalamnya sebuah masyarakat yang harus dibentuk, atau contoh yang lebih konkrit adalah sebuah lembaga kemasyarakatan atau negara yang harus diatur. ${ }^{1}$
Dengan melihat teori di atas, nampaklah bahwa agama memiliki konsep atau aturan tertentu terhadap seseọrang hidup dalam bernegara. Sehingga, jelaslah, bahwa di sini, agama memiliki peran dan pengaruh yang sangat besar terhadap format dan karakter negara. Meski tidak menutup kemungkinan bahwa agama-agama tertentu tidak memiliki konsep yang jelas tentang registrasi ini, namun dapat dilihat bahwa secara umum, agama memiliki aturan tentang itu. Adapun besar dan kecilnya porsi dari aturan kenegaraan itu, tentu saja tidak sama pada setiap agama. Meskipun dalam tesis sekularisasi peran agama yang seperti itu biasanya cenderung untuk hilang dan kemudian digantikan oleh peran birokrasi sekular, namun ternyata, tesis sekularisasi itu sendiri agaknya harus diberikan catatan lagi. Para kenyataannya, dalam agama tertentu, peran agama dalam registrasi itu ternyata masih sangat besar. Agama-agama tertentu masih sangat kuat mempengaruhi pengikutnya dalam hal mengatur masalah politik kenegaraan.

Islam dan Yahudi, adalah dua agama yang masih memelihara warisan ajaran-ajaran dan hukum agama mereka yang mentradisi. ${ }^{2}$ Apabila dilihat dari wacana sekularisasi, kedua agama ini relatif lebih rigid dari benturan sekularisasi. Keduanya, meski telah

'Turner Bryan S. 1997. Religion and Social Theory. London: Sage Publications. HIm. 133.

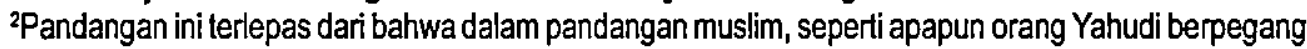
kepada apa yang mereka yakini sebagai ajaran agama mereka; Taurat dan Talmud, tetap saja mereka telah mengingkari bunyi Taurat yang sebenranya. Ini berdasar pada al-Qur'an bahwa dalam Kitab yang diterima oleh ahli kitab (Yahudi dan Nasrani) telah disebutkan bahwa kelak akan dibangkitkan seorang Nabi yang bemama Ahmad (Muhammad), dan ketika betul datang apayang disebutkan oleh kitab merekaitu(lnjil), mereka mendustakan Muhammad seraya menyatakan bahwa bukti-bukti kerasulan Muhammad itu tidak lain kecuali hanya "sihir yang nyata" baca QS. Al-Shaff $(61): 6$. 
melampaui era modern yang tidak singkat, telah bersentuhan dengan industrialisasi dan rasionalisasi kehidupan masih juga mereka meyakini agama, termasuk dalam masalah yang diistilahkan sosiologi agama disebut registrasi. Buktinya, dalam kedua agama ini masih sangat kuat dicita-citakan (dikehendaki) terbentukanya, atau terjaganya keberlangsungan apa yang disebut negara agama, atau jelasnya negara yang berlandaskan pada ajaran agama. Dalam kalangan muslim di hampir seluruh dunia, wacana negara Islam masih sangat jelas menjadi mainstream. Bahkan, ada semacam kecenderungan gelombang "Islamisasi" negara di berbagai tempat di mana mayoritas muslim berada. Untuk menyebut misalnya, Republik Islam Iran, Rezim Taliban (sebelum keruntuhannya akhir 2001), dan Sudan. Belum lagi yang masih dalam taraf wacana atau cita-cita. Tidak dipungkiri bahwa perjuangan muslim Moro (Philipina) ${ }^{3}$ ataupun beberapa gerakan di Indonesia ${ }^{4}$, cita-cita negara Islam masih sangat menonjol. Demikian juga dalam agama Yahudi, pendirian negara israel. adalah bukti nyata dari bahwa akar ideologis tidak mungkin dapat dilepaskan dari 'proyek' penegakan negara Israel. Tidàk terlalu sulit untuk mencari justifikasi dari sumber-sumber hukum agama (Taurat) maupun dari para fatwa para Rabbi
Yahudi akan keharusan pendirian negara Israel dalam kerangka berpikir Yahudi.

Dalam banyak hal, terdapat persamaan antara Islam dan Yahudi. Di antara kesamaan anatara keduanya, dalam kaitannya dengan masalah negara ini, keduanya merupakan agama yang kental nuansa hukumnya. Islam sangat dekat dengan istilah syariat (hukum), sedangkan Yahudi, atau ajarannya, sering disebut dengan "Law of Moses" atau hukumhukum yang dibawa oleh Musa. Isiam memiliki aturan hukum yang sangat banyak. Bahkan hampir dapat dikatakan bahwa keseluruhan ajaran Islam bersinggungan dengan hukum, kecuali beberapa hal saja. Sampai Schacht, orientalis yang banyak menekuni hukum Islam menyatakan bahwa "mustahil untuk dapat memahami Islam tanpa memahami hukum Islam itu sendiri" ${ }^{\text {5 }}$. Dalam Yahudi, demikian juga, sumber utama setelah Taurat, adalah Talmud, himpunan dari hukum-hukum Yahudi, yang lengkap di dalamnya dengan berbagai metode penarikan hukum. ${ }^{6}$ Karena cakupan hukumnya yang sangat besar itulah, maka tidak mustahil apabila dalam kedua agama tersebut, masalah politik masih banyak diatur. Agaknya, karena kuatnya perangkat hukum itulah, sehingga, kedua agama tersebut relatif masih resisten terhadap benturan sekularisasi.

${ }^{3}$ Gerakan-Gerakan semacam inilah yang oleh Barat biasa dianggap sebagai gerakan fundamentalisme Islam. Gatra. 1 September 2001.

${ }^{4} \mathrm{Hal}$ ini dibuktikan antara lain dengan masih senantiasa diungkit-ungkit nya masalah Piagam Jakarta di dalam perdebatan dalam opini publik maupun oleh siaran langsung.

5 Joseph Schacht. 1971. an Introduction to Islamic Law. Oxford: Oxford University Press. HIm. 1.

'Sumber hukum dalam Yahudi adalah Taurat, Misnah, Midrash, dan Talmud. Lihat, Manachem Elon. 1994. Jewish Law: History, Sources, Principles. Translated by Auerbach, Bernard \& Sykes, Melvin J. Jerusalem: Yhe Jewish Publication Society. HIm. 235-236. 
Pada akhirnya, jelaslah, bahwa dalam kedua agama tersebut, permasalahan yang berkaitan dengan kehidupan politik/ kenegaraan masih secara ketat diatur, karenanya wajar bila discourse tentang Negara Islam dan Negara Yahudi masih menjadi perbincangan yang aktual.

\section{Alasan-Alasan Pewujudan Negara Agama dalam Islam dan Yahudi}

Mengapakah kedua agama (Islam dan Yahudi) masih menghendaki terwujudnya negara agama? Dari pertanyaan tersebut tentu akan berusaha menyingkapkan rahasia, mengapa negara agama tetap masih diperlukan oleh orang Islam dan Yahudi.? Jawaban itu merupakan eksplorasi atas ajaran agama yang bagaimanakah yang memberikan dorongan bagi mereka dalam hal tersebut.

Alasan untuk pewujudan negara Islam dan Yahudi itu dapat dibagi ke dalam dua bagian; yakni alasan historis dan alasan normatif. Alasan historis dimasukkan mengingat bahwa perjalanan Nabi dan para sahabatnya, termasuk ketika mereka mendirikan kekuasaan politik (yang dalam bahasa modern disebut negara), akan menjadi referensi bagi tindakan dan perilaku pemeluk agama yang bersangkutan hingga pada masa ini. Namun, meski tindakan Nabi dapat dimaksudkan sebagai alasan normatif, namun penulis tetap dipisahkan antara keduanya dengan maksud ingin membedakan antara idea dan realita, sekaligus ingin melihat, bahwa terlepas dari ajaran itu diterimakan oleh nabi, bagaimanakah perjalanan yang dilalui oleh Nabi dalam kedua agama tersebut.

\section{Alasan Historis}

\section{Alasan Historis dalam Islam}

Dalam sejarah perjuangan Nabi Muhammad sangat jelas, Negara Madinah merupakan bagian yang tak terpisahkan dari proses dakwah Nabi menuju Islam yang mendunia. Bahkan, melihat keberhasilan dakwah Nabi itu dapat dicapai justeru setelah nabi Muhammad merintis pendirian negara Madinah. Melihat itu, maka, fase Makkah, seakan hanya merupakan sebuah persiapan, sebuah peletakan batu pondasi untuk selanjutnya merintis tegaknya sebuah komunitas muslim, yang diatur dengan aturan-aturan Islam, bukan hanya dalam masalah private (keperdataan), namun dalam masalah jinayah (pidana) hingga masalah as-siyar (hubungan antar negara atau hubungan internasional). Dengan tegaknya negara Madinah itu memungkinkan seluruh aturan Islam dapat diimplementasikan.

Meskipun dalam sejarah bithah (diutusnya Nabi sebaga rasul) itu dilalui 13 tahun di Makkah, masa yang justeru lebih panjang apabila dibandingkan dengan fase Madinah yang hanya berlangsung selama 10 tahun, namun lamanya waktu itu sama sekali tidak mengecilkan arti penting pendirian negara Madinah.

${ }^{7}$ Negara agama dalam Islam secara lebih tepat diistilahkan oleh Tahir Azhary, dengan nomokrasi Islam, yakni suatu sistem pemerintahan yang didasarkan pada asas-asas dan kaidah-kaidah hukum Islam (syari'ah). la merupakan "rule of Islamic Law'. Lihat Tahir Azhary. 1992. Negara Hukum. Jakarta: Bulan Bintang. Hlm. 65-66. 
Apakah dapat dikatakan bahwa kehidupan Nabi di Madinah itu merupakan bagian dari sejarah kenabian, di kalangan para ulama (intelektual Islam) juga muncul perbedaan pendapat. Ali bin Abdur-Raziq misalnya, sangat vokal menyatakan bahwa fakta bahwa Nabi itu menegakkan dan memimpin negara Madinah, bukanlah merupakan sebuah bagian dari misi suci kerasulan. ${ }^{8}$ Nabi menjadi rasul adalah suatu permasalahan tersendiri dan Nabi Muhammad menjadi pemimpin Madinah adalah sebuah masalah tersendiri yang lain. Namun, fakta historis bahwa Nabi menegakkan negara Madinah itu tetap menjadi catatan penting dari tarikh an-nabawi yang oleh umat Islam akan banyak dinapaktilasi, meskipun dengan improvisasi dalam pelaksanaannya.

Negara Madinah itu sendiri, sebenarnya merupakan sebuah komunitas sosial-politik yang dibangun di atas kota yang dulunya bernama Yatsrib. Hijrah Nabi, setelah gagal berbagai kali di berbagai tempat, akhirnya pilihan yang terakhir jatuh ke Madinah, setelah tentu saja berdasarkan apa yang dalam istilah kontemporer dikenal dengan 'study kelayakan' (feasibility study). Hijrah itu dilakukan setelah terjadinya dua momentum penting, baiah alaqabah awwal dan Bai'ah al-'Aqabah al-Tsani, yakni ikrar janji setia oleh orang-orang yang berasal dari Yatsrib untuk setia kepada Islam dan Rasulullah, yag itu terjadi dua tahap. ${ }^{9}$ Setelah kedatangan Nabi di Madinah, konstelasi sosial (struktur masyarakat) sama sekali berubah, masyarakat Yatsrib yang dahulunya selalu terlibat dalam konflik etnis (antar qabilah), setelah kedatangan Nabi Muhammad,konflik itu berhenti. Penerimaan masyarakat yang sangat baik terhadap kedatangan Nabi Muhammad, kemudian membawa pada sebuah keberuntungan sejarah yang sulit dicari bandingannya, ialah Nabi Muhammad diangkat menjadi pemimpin di antara semua segmen sosial di Yatsrib. Nabi bukan saja kemudian merubah nama Yatsrib, menjadi nama Madinah, sebuah nama yang kelak disadari memiliki arti yang sangat ideal, ${ }_{10}^{10}$ namun Nabi melakukan kontrak politik dengan menyusun dan menyepakati sebuah traktat perjanjian yang sangat monumental bukan hanya dalam sejarah Islam, namun juga dalam sejarah kenegaraan di dunia, yakni Piagam Madinah. "

¿Lihat sub judul tentang Pemikiran Politik Ali Abdul Raziq pada Munawir Sjadzali. 1993. Isalm dan Tata Negara Jakarta: UI Press. HIm. 140.

9Munawar Chalil. 1980. Kelengkapan Tarikh Nabi Muhammad saw. Jilid IIA Jakarta: Bulan Bintang.) HIm. 108-127 Lihatjuga J Suyuthi Pulungan. 1995. Figh Siyasah. Jakarta: Raja Grafindo Persada. HIm. 77-79.

${ }^{10}$ Kata-kata "madinah" yang berarti kota, ternyata satu rumpun derivasi (penurunan) dengan kata "madani" beradab (civil society) dan "madaniyyah" yang berarti peradaban, sehingga penamaan itu sebenarnya mengandung rahasia yang sangat dalam, sebuah komunitas yang diharapkan agar manusia-manusia dalam kelompok tersebut bisa menjadi manusia yang beradab, masyarakat madani.

"1Piagam madinah ini juga menjadi sejarah penting kenegaraan di dunia, karena piagam ini merupakan konstitusi tertulis yang pertama di dunia. Konstitusi Athena, misalnya, meski telah lebih dahulu lahir dibandingkan dengan Piagam madinah, namun konstitusi Athena ditulis oleh Aristoteles, jadi dia tidak merupakan sebuah konstitusi yang tertulis, atau setidaknya, terkodifikasi dengan baik. Lihat Aristotle. The Athenian Constitution. 1984. Terjemah ke bahasa Inggris oleh Rhodes P.J. Middlesex. 


\section{Alasan Historis dalam Yahudi}

Bentuk alasan semodel di atas, juga yang terjadi dengan sejarah Yahudi. Berdirinya negara Israel tahun 1948 mengindikasikan lahirnya sebuah negara Yahudi modern yang baru. Sering disebutkan bahwa negará inj merupakan realisasi dari cita-cita orang Yahudi. Mereka menginginkan agar dapat kembali lagi ke Palestina setelah terusirnya (exile) mereka pada tahun $400 \mathrm{M}$.

Masalah kedua adalah masalah kepentingan agama. Maksudnya, Masjidil Aqsa adalah tempat suci dan bersejarah bukan saja milik Islam (sebagai tempat suci ketiga setelah Masjid al-Haram dan Masjid alNabawi), namun dia juga tempat suci bagi Yahudi. Dalam tingkat tertentu, itu adalah juga tempat suci bagi kaum Kristiani. Kawasan alAqsha (termasuk the Temple Mount) adalah peninggalan sejarah suci yang dibangun oleh Nabi Daud as (King David) yang di masa kejayaannya diteruskan oleh Nabi Sulaiman (King Salomon) adalah bagian penting dari sejarah agama Samawi (Abrahamic Religion).(Hoiberg,2001). Bukan hanya itu, kawasan Jerusalem pada umumnya adalah sebuah area yang. sangat bersejarah bagi ketiga agama tersebut. Oleh karenanya, Palestina itu dalam terminologi Yahudi merupakan Eretz Hakedosah serta dalam terminologi Kristen adalah the Holy Land. Dalam terminologi Islam, Jerusalem biasa disebut Baitul Maqdis atau Baitul Muqaddas. Pada masa Islam klasik, sebagai yang ditulis oleh al-Thabari, kota ini dinamakan dengan
Iliya' madinat bait al-maqdis, ${ }^{12}$ sehingga masing-masing dari ketiga agama tersebut memiliki kepentingan ideologis tèrhadap Jerusalem. Karena itulah, masing-masing selalu berjuang gigih untuk dapat mempertahankan penguasaan, atau minimal akses yang mudah, terhadap tempat-tempat suci tersebut. Untuk ini, mereka siap untuk melakukan perjuangan atas nama agama.

\section{Alasan Normatif}

\section{Alasan dalam Agama Islam}

a. Khilafah fil ardh

Di antara alasan pokok penegakan sebuah negara dalam Islam, adalah kekhalifahan, dan ini sangat terkaił dengan filosofi penciptaan manusia. Allah menciptakan manusia agar manusia itu menjadi khalifah di muka bumi. Doktrin ini didasari oleh banyak ayat dalam al-Qur'an, antara lain dalam QS. Al-Nur: 55:

"Dan Allah telah berjanij kepada orangorang yang beriman di antara kamu dan mengejakan amal-amal yang saleh bahwa Dia sungguh-sungguh akan menjadikan mereka berkuasa di bumi sebagaimana Dia telah menjadikan orang-orang yang sebelum mereka berkuasa...... (Hendaknya) mereka tetap menyembahKu dengan tiada mempersekutukan sesuatu pun dengan Aku..."

12S.D. Goitein. "Al- Kuds" 1999. Dalam. Tp. The Encyclopaedia of Islam. CD Rom. Edition V. 1.0. Leiden: Koninklijge Brill NV. 
Khalifah, sebagaimana dalam as-siyasah juga dikenal dengan istilah lain, yaitu amir, malik, dàn sulthan, yang berarti pemimpin. Manusia sebagai pemimpin di muka bumi berarti manusia itu harus menjadi pengelola di muka bumi ini, menjaga agar bumi ini dapat dimanfaatkan dan dikelola dengan baik, sesuai dengan kebutuhan manusia. Terminologi khalifah, tidak dapat dilepaskan dari konotasi kekuasaan politis, karena tidak mungkin menegakkan kekhalifahan tanpa dengan menggunakan kekuasaan politik. Pengelolaan bumi dan seisinya pun tidak dapat juga dilepaskan dari keharusan memiliki kekuasaan politik. Karenanya, konsep kekhalifahan manusia di muka bumi, biasa dipahami, secara inherent pewujudan kekhalifahan dalam arti politik pun tercakup.

Doktrin khilafah ini juga mengimplikasikan manusia bukanlah penguasa atau pemilik dirinya sendiri, tetapi ia hanyalah wakil dari Allah swt. Adapun sistem pemerintahan yang memalingkan diri dari Allah, lalu menjadi sistem yang terlepas bebas, memerintah dengan dirinya sendiri, untuk dirinya sendiri, maka, menurut Al-Maududi, itu bukanlah khilafah, tapi itu adalah pemberontakan atau kudeta melawan Sang Penguasa yang hakiki. $^{13}$

\section{b. Penegakan Hukum}

Seruan tentang penegakan hukum (syari'at) memang mendapatkan porsi yang sangat besar dalam Islam. Bahkan dalam kaitannya dengan ini, dikenal konsep al-
Hakimiyah al-llahiyah atau kepemerintahan yang bersifat ketuhanan. Konsep ini memiliki konsekuensi-konsekuensi sebagai berikut:

Pertama, Tuhan Pemelihara alam semesta ini, pada hekikatnya Tuhan Pemelihara manusia, dan tidak ada jalan lain baginya kecuali patuh dan tunduk kepada sifat ketuhanan-Nya Yang Maha Esa. Kedua, hak untuk menghakimi dan mengadili tidak dimiliki oleh siapapun kecuali Allah. Manusia wajib taat kepadaNya dan beribadat kepadaNya, dan inilah jalan yang benar dan perilaku yang lurus. Ketiga, hanya Allah sendiri yang memiliki hak mengeluarkan hukum, sebab Dia-lah satusatunya Pencipta. ${ }^{14}$

Dari beberapa poin tersebut menunjukkan bahwa kepentingan untuk mengaktualisasikan hukum syari'at menjadi dasar yang penting bagi ide penegakan negara Islam. Setidaknya, hal ini merupakan indikasi bahwa Islam dengan intensitas yang relatif tinggi berhasrat untuk campur tangan dan mengatur kehidupan politik kenegaraan bagi penganutnya.

\section{c. Tatanan Dunia yang Ideal}

Terwujudnya tatanan dunia yang ideal menurut syari'at Islam juga merupakan alasan yang penting mengapa islam mesti berbicara tentang politik ketatanegaraan. Minimal ada dua hal yang perlu dicatat dalam kaitannya dengan pewujudan tatanan dunia yang ideal ini. Pertama, negara bertujuan untuk menegakkan keadilan dalam kehidupan manusia dan menghentikan kezaliman serta menghancurkan kesewenang-wenangan. Kedua, menegakkan sistem yang membentuk sisi terpenting dalam kehidupan Islam, yakni

\footnotetext{
${ }^{13}$ Maududi. Op.Cit. Hlm. 65-66. Lihat juga, Azhary. Op.Cit. HIm. 79.

${ }^{14}$ Maududi. Op.Cit. 53-55.
} 
negara dapat menyebarkan kebaikan, memerintahkan yang ma'ruf, memotong akarakar kejahatan serta melarang yang munkar.

Dengan demikian, Islam mengatur masalah kehidupan politik umatnya, dengan maksud agar kekuasaan politik atau kepemimpinan itu dimanfaatkan untuk menciptakan tatanan kehidupan yang baik, yang membawa kepada kebaikan bagi umat manusia. $^{15}$

\section{Alasan dalam Agama Yahudi}

Dalam agama Yahudi, pendirian negara Yahudi di Israel memiliki alasan-alasan normatif, alasan yang berupa ketentuan hukum, yang terdapat dalam ajaran agama Yahudi. Setidaknya, ada dua alasan penting:

\section{a. Pendirian Kerajaan Tuhan (Kingdom of God)}

Kata-kata "Yahudi" (al-Yahud, Jewish), termasuk dalam kaitanya dengan negara Yahudi Israel, memberikan konotasi bukan hanya sebuah bangsa, tetapi juga sebuah agama, sehingga ajaran dan hukum agama Yahudi itu mestilah menjadi salah satu faktor penting yang mendasari berdirinya negara lsrael serta mendasari juga perkembangan lebih lanjut dari negara tersebut.
Dalam kalimat-kalimat awal dari teks deklarasi kemerdekaan Israel disebutkan bahwa alasan mengapa tanah Palestina telah dipilih untuk menjadi lokasi bagi negara Yahudi modern adalah karena itu adalah suatu tempat di mana identitas agama dan politik orangorang Yahudi dahulu dibentuk, "Eretz Yisrael (Land of Israel) was the birthplace of the Jewish people. Here, their spiritual, religious and political identity was shaped" 16

Rabbi Maimon (1875-1962), salah seorang yang dinilai penting dalam jajaran pimpinan Zionisme menyatakan bahwa negara Yahudi harus didirikan sesuai dengan prinsip agama Yahudi, yakni Taurat yang dimiliki orang Israel. "Keyakinan kita jelas, sejauh ini, bangsa ini melihat bahwa agama dan negara adalah dua hal yang saling membutuhkan". ${ }^{17} \mathrm{Di}$ sini, jelaslah bahwa faktor yang kuat yang mendorong orang-orang Yahudi untuk mendirikan negara dan menentukan tempat di mana negara dimaksud harus didirikan, adalah faktor keagamaan. Dengan kata lain, keputusan politik mereka disetir oleh sebuah Kekuasaan llahiah (divine authority). Untuk lebih jauh memahami masalah ini, perlu dipahami pula konsep yang terdapat dalam hukum agama Yahudi, ialah konsep tentang kerajaan Tuhan dan Messianisme.

${ }^{15}$ Poin ini (Pewujudan tatanan sosial politik yang ideal) ini merupakan rangkuman atas berbagai tujuan pemerintahan dalam Islam, yang dalam berbagai literatur sering disebut secara terpisah-pisah, misalnya, tujuan kesejahteraan, tujuan keadilan, tujuan persamaan, dans ebagainya. Lihat Maududi. Op.Cit. HIm. 75-76 dan Azhary. Op.Cit. HIm. 85-111).

${ }^{16}$ The Declaration of Establishment. Dalam Baker, Henry E. 1968. The Legal System of/srael. London: Israel Universities Press. HIm. 2-5.

${ }^{17 P i l k i n g t o n, ~ C M . ~ 1995 . ~ J u d a i s m . ~ L o n d o n: ~ H o d d e r ~ H e a d l i n e . ~ H I m . ~} 222$. 


\section{b. Kebangkitan Messiah}

Dalam sejarah Yahudi didapatkan, bahwa istilah tanah Israel (eretz of Israel) itu sendiri berasal dari hukum agama mereka. 'Israel' adalah nama yang diberikan kepada Ya'kub. ${ }^{18}$ Ya'kub a.s. adalah seorang yang meyakini terhadap apa yang dijanjikan oleh Tuhan kepada Ibrahami akan sebuah bumi yang dijanjikan untuk para pengikutnya. Tempat itulah yang kemudian disebut dengan tanah yang disucikan (eretz hakedosah, the holy land). Sejarah dengan jelas menunjuk, bahwa keyakinan untuk mendirikan Kerajaan Tuhan adalah berkait erat dengan tanah yang dijanjikan ini. Hal ini sangat erat berkait dengan Kerajaan Nabi Daud (David's Kingdom). Setelah Raja Daud menjadikan tanah Israel itu sebagai ibu kota kerajaannya, kota Jerussalem menjadi signifikan, merupakan tempat di mana ibadah dan pengabdian kepada Tuhan dipusatkan. Maka, berkumpulnya orang Yahudi setelah lama terusir, dan pengembalian tanah suci tersebut merupakan suatu harapan yang selalu diekspresikan (dalam Isaiah, 51:3, 52:1-1, 57: 7-10). Dalam ayat-ayat tersebut, istilah 'Zion' juga disebut, sehingga Zionisme bisa diartikan sebagai harapan dan cita-cita tersebut. ${ }^{19}$

Pendirian negara Israel juga ada kaitannya dengan Messianisme. Dalam agama Yahudi, messianisme adalah keyakinan bahwa akan datang Messiah, yaitu orang yang ditunjuk oleh Tuhan untuk turun ke bumi di akhir dunia, untuk memimpin kaumnya sebagai seorang raja (king), membebaskan mereka dari segala bentuk penindasan dan ketidakadilan, dalam membawa Kerajaan Tuhan ke dunia ini. Sebagian orang Yahudi berkeyakinan bahwa pendirian negara Israel tahun 1948 merupakan wujud datangnya Messiah. Sebagian juga meyakini untuk tidak lagi mengharap-harap turunnya Messiah di bumi ini. ${ }^{20}$

Itu semua menunjukkan, betapa latar belakang keagamaan (hukum agama) berdiri sangat kokohnya di belakang inspirasi pendirian negara Israel. Konsep tentang Kerajaan Tuhan yang melekat dalam hukum agama mereka, teologi Messianisme yang mereka yakini, adalah bagian yang sangat dipegang teguh. Tidaklah mustahil, bahwa kemudian muncul sebuah istilah baru tentang 'the redemption of /srael' (pertobatan orang Israel). Istilah itu digunakan untuk menyebut keseluruhan proses kembalinya mereka ke Palestina serta pendirian negara Israel. (The Declaration, dalam Baker, 1968: 2). Semangat pertobatan inilah yang memberikan spirit kepada mereka untuk selalu berjuang secara konsisten untuk bisa berkumpul kembali di tanah yang disucikan itu dan mendirikan sebuah negara Yahudi. Untuk pertobatan itulah, orang Yahudi siap menghadapi segala macam kesulitan dan perjuangan panjang yang harus mereka lalui untuk pendirian

${ }^{18}$ Ahmad Shalaby. 1990. Perbandingan Agama, Agama Yahudi. Terjemah Syamsudin Manaf. Surabaya: Bina llmu. HIm. 20.

${ }^{19} \mid$ zhak Englard. 1975. Religious Law in The Israel Legal System. Jenusalem: Hebrew University of Jerusalem. HIm. 168.

${ }^{20}$ Richard Kennedy. 1984. The Dictionary of Beliefs. London: Ward Lock Educational. HIm. 123. 
negara Israel. Kenyataan akan kesulitankesulitan itu sudah disadari oleh mereka, sebagaimana yang diungkapkan oleh Z.H. Kallischer:

"The redemption of Israel, for which we long, is not to be imaged as sudden miracle. The Almighty, praised be His name, will not suddenly descend from on high and command His people to go forth. He will not send his Messiah from heaven in a twinkling of eye, to sound the great trumpet for the scattered of Israel and gather them into Jerusalem. ${ }^{21}$

Berdirinya negara Israel sangat kental diwarnai oleh semangat keagamaan orang Yahudi. Berbagai aspek keyakinan dan hukum agama yang ada pada mereka jelas menuntut mereka untuk dapat kembali ke tanah di mana mereka dahulu telah mendiami dan membangun sebuah kerajaan besar. Keyakinan yang seperti itu juga menuntut mereka untuk membangun lagi sebuah kerajaan/negara baru.

\section{c. Penerapan Hukum Agama}

Poin ini juga merupakan alasan penting bagi pendirian negara Israel. Salah satu keinginan orang Yahudi adalah agar mereka, dalam negara israel itu, dapat memberlakukan hukum agama mereka. Meskipun dalam masa transiși beberapa waktu setelah berdirinya negara itu sumber hukum yang dipakai masih bermacam-macam, seperti hukum Turki Utsmani, Hukum Inggris (karena
Israel/Palestine pernah menjadi wilayah di bawah kekuasaan Inggris) dan produk hukum dari Komisi Agung untuk Palestina. Namun, sangat nampak dalam perkembangannya bahwa Yahudi ingin menerapkan apa yang mereka yakini dari kitab-kitab suci mereka. Termasuk di dalamnya, bahwa kemudian Bahasan lbrani menjadi bahasa nasionainya, hari-hari libur (Sabath, misalnya) dan hari besar semua dilakukan dalam konteks ajaran Yahudi.

Di Israel, penerapan hukum Yahudi ditangani oleh Pengadilan para Rabbi (Rabbinical Courts). Dalam kenyataannya, tidak semua hukum Yahudi bisa diterapkan. Inilah, yang antara lain menjadi polemik besar di kalangan Yahudi, utamanya antara sekte ortodox dan progressif. Namun, terlepas darj adalah tarik-ulur permasalahan pelaksanaan hukum Yahudi ini, tetap saja, bahwa seberapapun juga intensitasnya, orang Yahudi tetap ingin memberlakukan/mengimplementasikan hukum agama mereka.

Dari sebuah perbandingan singkat tersebut di atas, nampaklah bahwa ada semacam kesamaan pola (pattern) dalam alasan-alasan periunya penegakan negara agama, baik dalam alasan historis maupun alasan normatif. Ketiga alasan normatif tersebut, yang merupakan kristalisasi dari berbagai alasan yang ada, menunjukkan banyak kesamaan corak. Sejak dari alasan untuk mendirikan khilafah, yang dalam terminologi Yahudi sangat dekat dengan istilah the Kingdom of God, juga alasan mewujudkan tatanan sosial-politik yang ideal, masyarakat

${ }^{21}$ Z.H. Kallischer. 1998. "The Redemption of Israel." Dalam Gwilym Beckerlegge (ed). The World Religions, Reader. London: Routledge. HIm. 53. 
yang baik, itu juga merupakan alasan-alasan yang tidak asing dalam keduanya. Ditambah dengan, alasan untuk mengimplementasikan hukum-hukum dan ajaran agama, kian lengkaplah kemiripan antara keduanya:

\section{Simpulan}

Meskipun di zaman modern seperti sekarang ini, di mana sekularisasi telah melanda berbagai pandangan hidup manusia, namun ternyata, masih ada sebagian dari pandangan manusia yang belum hancur oleh sekularisasi itu, termasuk di sini adalah pandangan tentang keharusan pengaturan politik kenegaraan dengan aturan agama di kalangan pemeluk Islam dan Yahudi.

Ada pattern-pattern (pola) yang mirip antara agama Islam dan Yahudi dalam hal alasan-alasan perlu didirikan dan ditegakkannya 'negara agama' yang diatur dengan hukum-hukum agama. Alasan itu berupa: alasan historis, keduanya sama-sama menjadikan sejarah Nabi mereka sebagai pembenar perjuangan politik, serta alasan normatif; yaitu perlunya menunaikan perintah agama untuk mewujudkan kekuasaan Tuhan di bumi (Khilafah/Kingdom of God), tatanan politik yang ideal, serta perlunya membikan tatanan politik yang memungkinkan terimplementasikannya hukum-hukum dan ajaran agama, kesemuanya itu memiliki kemiripan pola.

\section{Daftar Pustaka}

S, Turner Bryan. 1997. Religion and Social Theory. London: Sage Publications.

Schacht, Joseph. 1971. an Introduction to Islamic Law . Oxford: Oxford University Press.

Elon, Manachem. 1994. Jewish Law: History, Sources, Principles. Translated by Auerbach, Bernard \& Sykes, Melvin J. Jerusalem: Yhe Jewish Publication Society.

Azhary, Tahir. 1992. Negara Hukum. Jakarta: Bulan Bintang.

Sjadzali, Munawir. 1993. Isalm dan Tata Negara Jakarta: UI Press.

Chalil, Munawar. 1980. Kelengkapan Tarikh Nabi Muhammad saw. Jilid IIA Jakarta: Bulan Bintang.)

Pulungan, J Suyuthi. 1995. Fiqh Siyasah. Jakarta: Raja Grafindo Persada.

Aristotle. The Athenian Constitution. 1984. Terjemah ke bahasa Inggris oleh Rhodes P.J. Middlesex.

Goitein, S.D. "Al- Kuds" 1999. Dalam. Tp. The Encyclopaedia of Islam. CD Rom. Edition V. 1.0. Leiden: Koninkligge Brill NV.

E, Baker, Henry. 1968. The Legal System of Israel. London: Israel Universities Press.

CM, Pilkington,. 1995. Judaism. London: Hodder Headline.

Shalaby, Ahmad. 1990. Perbandingan Agama, Agama Yahudi. Terjemah Syamsudin Manaf. Surabaya: Bina. 
Englard, lzhak. 1975. Religious Law in The Kallischer, Z.H.. 1998. "The Redemption of Israel Legal System. Jerusalem: Hebrew University of Jerusalem.

Kennedy, Richard. 1984. The Dictionary of

Beliefs: London: Ward Lock Gatra. 1 September 2001. Educational. Israel." Dalam Gwilym Beckerlegge (ed). The World Religions, Reader. London: Routledge.

(1) (1) 